\title{
Medial-Frontal Stimulation Enhances Learning in Schizophrenia by Restoring Prediction Error Signaling
}

\author{
Robert M.G. Reinhart, Julia Zhu, @Sohee Park, and Geoffrey F. Woodman \\ Department of Psychology, Center for Integrative and Cognitive Neuroscience, Vanderbilt Vision Research Center, Vanderbilt University, Nashville, \\ Tennessee 37240
}

Posterror learning, associated with medial-frontal cortical recruitment in healthy subjects, is compromised in neuropsychiatric disorders. Here we report novel evidence for the mechanisms underlying learning dysfunctions in schizophrenia. We show that, by noninvasively passing direct current through human medial-frontal cortex, we could enhance the event-related potential related to learning from mistakes (i.e., the error-related negativity), a putative index of prediction error signaling in the brain. Following this causal manipulation of brain activity, the patients learned a new task at a rate that was indistinguishable from healthy individuals. Moreover, the severity of delusions interacted with the efficacy of the stimulation to improve learning. Our results demonstrate a causal link between disrupted prediction error signaling and inefficient learning in schizophrenia. These findings also demonstrate the feasibility of nonpharmacological interventions to address cognitive deficits in neuropsychiatric disorders.

Key words: error-related negativity; executive control; learning; medial-frontal cortex; schizophrenia; transcranial direct-current stimulation

\section{Significance Statement}

When there is a difference between what we expect to happen and what we actually experience, our brains generate a prediction error signal, so that we can map stimuli to responses and predict outcomes accurately. Theories of schizophrenia implicate abnormal prediction error signaling in the cognitive deficits of the disorder. Here, we combine noninvasive brain stimulation with large-scale electrophysiological recordings to establish a causal link between faulty prediction error signaling and learning deficits in schizophrenia. We show that it is possible to improve learning rate, as well as the neural signature of prediction error signaling, in patients to a level quantitatively indistinguishable from that of healthy subjects. The results provide mechanistic insight into schizophrenia pathophysiology and suggest a future therapy for this condition.

\section{Introduction}

Theories of learning and goal-directed behavior seek to explain how success and failure are used to improve future decisions (Sutton and Barto, 1998; Haggard, 2008). Central to these theories is the concept of prediction error. A prediction error signal is generated when outcomes deviate from predictions, leading to the updating of values associated with available actions (Walton

Received May 2, 2015; revised July 28, 2015; accepted Aug. 2, 2015.

Author contributions: R.M.G.R., S.P., and G.F.W. designed research; R.M.G.R. and J.Z. performed research; R.M.G.R. analyzed data; R.M.G.R., S.P., and G.F.W. wrote the paper.

This work was supported by National Institutes of Health Grants R01-EY019882, R01-EY025275, R01-MH073028, P30-EY08126, P30-HD015052, T32-EY007135, and F31-MH102042 and National Alliance for Research on Schizophrenia and Depression. We thank Lindsey G. McIntosh, Channing Cochran, Laura Hieber, and Jamie Michael for providing clinical operations support.

The authors declare no competing financial interests.

Correspondence should be addressed to either Dr. Sohee Park or Dr. Geoffrey F. Woodman, Vanderbilt University, 2301 Vanderbilt Place, PMB 407817, Nashville, TN 37240-7817. E-mail: sohee.park@vanderbilt.edu or geoffrey.f.woodman@vanderbilt.edu.

DOI:10.1523/JNEUROSCI.1717-15.2015

Copyright $\odot 2015$ the authors $\quad 0270-6474 / 15 / 3512232-09 \$ 15.00 / 0$ et al., 2004; Brown and Braver, 2005; Behrens et al., 2007; Matsumoto et al., 2007; Alexander and Brown, 2011). Prediction errors are thought to be computed by the midbrain dopamine system and signaled to the medial-frontal cortex where they are used to adjust stimulus-response mappings (Schultz and Dickinson, 2000).

The error-related negativity (ERN) serves as a putative electrophysiological signature of the prediction error signal in the brain (Holroyd and Coles, 2002; Frank et al., 2005; Jocham and Ullsperger, 2009; Gehring et al., 2012). The ERN is observed over medial-frontal cortex as a negative potential following behavioral errors relative to correct responses. It is thought to reflect a mismatch between the actual response and the predicted response, with the size of the ERN proportional to the magnitude of this mismatch (Holroyd and Coles, 2002; Frank et al., 2005; Jocham and Ullsperger, 2009; Gehring et al., 2012). The precise neuropharmacological basis of the ERN is currently debated (Jocham and Ullsperger, 2009; Gehring et al., 2012). For example, the ERN may be solely determined by the midbrain dopamine 
A

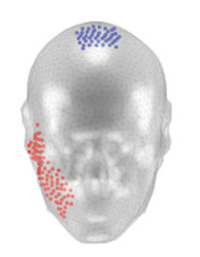

Montage

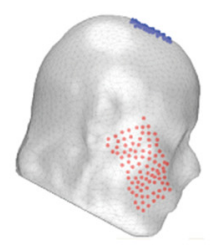

Model

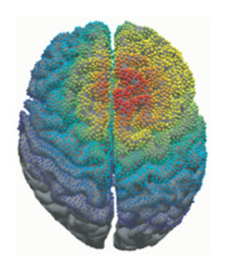

B

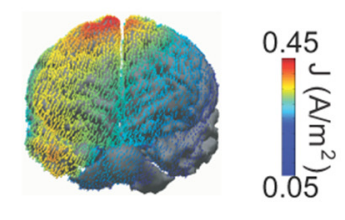

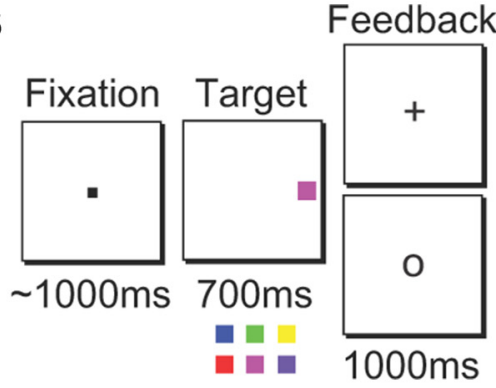

Figure 1. TDCS model and task. $A$, Schematic of tDCS montage, and the modeled distribution of current flow during anodal stimulation on top and front views of a $3 D$ reconstruction of the cortical surface. $\boldsymbol{B}$, The reinforcement learning task requiring subjects to map the color of the target (red vs blue, magenta vs green, or purple vs yellow) to a button on a handheld gamepad.

system (Holroyd and Coles, 2002), or another neurotransmitter may give rise to the ERN, which causes a dopaminergic response in the basal ganglia (Frank et al., 2005).

Faulty prediction error signaling has been suggested to be central to schizophrenia (Corlett et al., 2007; Murray et al., 2008; Fletcher and Frith, 2009) associated with a broad range of clinical symptoms. Reduced ERN amplitude has been linked to the negative (Bates et al., 2002; Morris et al., 2011; Foti et al., 2012; Mathalon and Ford, 2012) and positive symptoms (Bates et al., 2002; Mathalon et al., 2002) of schizophrenia. For example, the dysfunction of the neural mechanisms, thought to compute prediction error and signal this computation to the cortex, may underlie the discounting of rewarding events giving rise to negative symptoms, such as impairments in motivation and anhedonia (Gold et al., 2012). Moreover, faulty predictions about the world result in discrepancies between the expected and observed outcomes, which may serve as input for delusions and paranoia, core features of positive symptoms (Hemsley, 2005; Corlett et al., 2010; Corlett and Fletcher, 2012).

Here we sought to establish the first causal link between disrupted prediction error signaling and learning rate deficits in schizophrenia. We also sought to improve the performance of patients by increasing the ERN through the exogenous modulation of cortical activity. To achieve these goals, we delivered transcranial direct-current stimulation (tDCS) over the medial-frontal cortex (Fig. 1A). We applied 20 min of anodal tDCS because this duration and current-flow direction have been shown to increase activity, with effects lasting up to $5 \mathrm{~h}$ in duration (Reinhart and Woodman, 2014, 2015a, b; Reinhart et al., 2015). Each subject completed anodal and sham conditions on different days with order randomized across subjects, and subjects being blind to the stimulation conditions (for details and control analyses, see Materials and Methods). Immediately following stimulation, we recorded subjects' response-locked ERN while they performed a learning task that allowed us to measure prediction error signaling in the brain (Fig. 1B) (Holroyd and Coles, 2002; Reinhart and Woodman, 2014). We used a $700 \mathrm{~ms}$ deadline and randomly interleaved stop signals to stretch stimulus-response learning across the first $25-30$ trials, and reliably measure the ERN.

\section{Materials and Methods}

Subjects. We recruited individuals who met the Diagnostic and Statistical Manual of Mental Disorders, Fourth Edition criteria for schizophrenia from outpatient psychiatric facilities in Nashville. Diagnoses were confirmed with structured clinical interviews (Structured Clinical Interview for DSM-IV Axis I Disorders) (First et al., 1995). All patients were medicated. Symptoms were assessed with the Brief Psychiatric Rating Scale (Overall and Gorham, 1962), the Scale for the Assessment of Positive Symptoms (Andreasen, 1984), and the Scale for the Assessment of Negative Symptoms (SANS) (Andreasen, 1983). Subjects were excluded if they met any of the following criteria: substance use within the past 6
Table 1. Demographic information ${ }^{a}$

\begin{tabular}{lllcl}
\hline & Patients & Controls & Statistical test & $p$ \\
\hline Age, years & $43.1(7.76)$ & $38.2(10.78)$ & $t=1.59$ & 0.12 \\
Gender, $n$ & & & $\chi^{2}=0.003$ & 0.96 \\
$\quad$ Female & 8 & 8 & & \\
$\quad$ Male & 11 & 10 & & \\
Years of education & $12.6(1.98)$ & NA & & \\
Duration of illness, years & $22.6(7.86)$ & NA & & \\
SAPS, total & $16.8(15.37)$ & NA & & \\
SANS, total & $31.7(16.92)$ & NA & & \\
BPRS & $18.6(10.60)$ & NA & & \\
CPZ dose equivalent & $425.05(250.73)$ & NA & & \\
& $\mathrm{mg} / \mathrm{kg} / \mathrm{d}$ & & & \\
& & & & \\
\hline
\end{tabular}

${ }^{a}$ Data are mean (SD). $t=$ independent two-tailed $t$ test. SAPS, Scale for the Assessment of Positive Symptoms; SANS Scale for the Assessment of Negative Symptoms; BPRS, Brief Psychiatric Rating Scale; NA, not applicable.

months, neurological disorders, history of head injury, inability to fixate, and excessive sleepiness. All subjects had normal color vision, and normal or corrected-to-normal visual acuity. All subjects gave written informed consent approved by the Vanderbilt Institutional Review Board and were financially compensated for their participation.

We first performed a power calculation to estimate the necessary sample size from a pilot study of 10 subjects who received sham and anodal stimulation on different days. We pooled mean differences and SDs of our dependent variables across stimulation conditions to conservatively estimate Cohen's $d$ effect size based on paired samples two tailed $t$ tests (accuracy: $d=2.34$, reaction time [RT]: $d=1.50$, ERN: $d=1.51$ ). We found that a sample size of 18 subjects would be sufficient to detect effects of the same magnitude with $80 \%$ power at the $p=0.05$ significance level.

In the present study, analyses were conducted on 19 patients with schizophrenia (11 male, 8 female), and 18 demographically matched healthy subjects ( 10 male, 8 female). Seventeen patients completed both anodal and sham conditions, 1 patient completed only anodal, and 1 patient completed only sham. All 18 healthy subjects completed both anodal and sham conditions. However, the same patterns of effects were observed across all dependent variables when our analyses were restricted to the 17 patients and 18 control subjects who participated in both stimulation conditions. Subjects in each group were matched on age, gender, and handedness (for demographic information, see Table 1).

Stimuli and procedure. Each subject was exposed to $20 \mathrm{~min}$ of anodal and sham tDCS on different days, with order randomized across subjects (see below for details about the stimulation) (Fig. 1A). Immediately following stimulation, we recorded the subject's event-related potentials while they performed a feedback-based, learning task. During this task, the subjects needed to learn which button to press on a handheld gamepad when each possible target color was presented. Subjects needed to respond within a $700 \mathrm{~ms}$ response deadline unless the target was followed by a stop signal (Fig. 1B).

Each trial began with the presentation of a central fixation point $\left(0.37^{\circ}\right.$ square, $\left.30 \mathrm{~cd} / \mathrm{m}^{2}, 800-1200 \mathrm{~ms}\right)$. Next, a colored-square target $\left(1^{\circ} \times 1^{\circ}\right.$, $10^{\circ}$ from the center of screen along the horizontal meridian, $700 \mathrm{~ms}$ ) appeared to the left or right of fixation. The target appeared in one of two 
possible colors on each trial; the details of the color assignment across days and subjects are described below. On half of the trials, the target was to the left of fixation, and the target was to the right of fixation on the remainder of the randomly interleaved trials. On 33\% of all trials, a stop signal was presented following the target (a central square subtending $0.66^{\circ}$, with $0.08^{\circ}$ line width, $30 \mathrm{~cd} / \mathrm{m}^{2}$ ), informing subjects to withhold their response. These stop-signal trials were randomly interleaved with target-only trials. Six stop-signal delays (the stimulus-onset asynchrony between the onset of the target and the onset of the stop signal) were sampled with equal probability: 60, 120, 180, 240, 300, and $360 \mathrm{~ms}$. After presentation of the stop signal, stimuli remained on the screen until $700 \mathrm{~ms}$ had elapsed from target onset. The intertrial interval was 1000-1200 ms, randomly jittered with a rectangular distribution. Session duration was $\sim 1 \mathrm{~h}$.

Consistent with previous learning manipulations (Holroyd and Coles, 2002; Reinhart and Woodman, 2014), subjects were required to learn which of two buttons on the handheld gamepad corresponded to which target color. Between testing days (i.e., stimulation conditions), the target colors changed. This required subjects to relearn the stimulusresponse mapping on each day. On any given testing day, target stimuli could appear in 1 of 3 pairs of colors (red, $x=0.612, y=0.333,15.1$ $\mathrm{cd} / \mathrm{m}^{2}$ and blue, $x=0.146, y=0.720,6.41 \mathrm{~cd} / \mathrm{m}^{2}$; magenta, $x=0.295$ $y=0.153,19.3 \mathrm{~cd} / \mathrm{m}^{2}$ and green, $x=0.281, y=0.593,45.3 \mathrm{~cd} / \mathrm{m}^{2}$; or purple, $x=0.245 y=0.126,9.3 \mathrm{~cd} / \mathrm{m}^{2}$, and yellow, $x=0.408, y=0.505$, $54.1 \mathrm{~cd} / \mathrm{m}^{2}$ ). The color pairs and the color-to-button mappings were randomized across days, with the order of each color-to-button mapping randomized across subjects.

We presented feedback at the end of every trial so that subjects could learn the stimulus-response mappings across trials. Feedback occurred $1000 \mathrm{~ms}$ after the $700 \mathrm{~ms}$ response window had lapsed, and its probability was fully deterministic. Feedback was a centrally presented outline of a circle $\left(0.88^{\circ}\right.$ diameter, $0.13^{\circ}$ thick $)$ or cross $\left(0.88^{\circ}\right.$ length, $0.13^{\circ}$ thick $)$ lasting for $1000 \mathrm{~ms}$, with the meaning of these symbols (i.e., correct vs incorrect) randomized across conditions and subjects. Subjects were not informed of the stimulus-response mappings, and had to determine the optimal response strategy on a trial-and-error basis. Subjects were instructed, and motivated by feedback on every trial, to learn the correct stimulus-response mappings while also responding as quickly as possible, and inhibiting their responses to the randomly interleaved stop signals.

$t D C S$. We applied tDCS using a battery driven, constant current stimulator (Mind Alive) and pair of conductive rubber electrodes (active: $19.25 \mathrm{~cm}^{2}$ reference: $52 \mathrm{~cm}^{2}$ ). The electrodes were placed in salinesoaked sponges and held in place by a headband. The reference electrode was placed on the center of the right cheek to avoid confounding effects from other brain regions (Tseng et al., 2012; Reinhart and Woodman, 2014). The cheek electrode was placed diagonally, $3 \mathrm{~cm}$ from the cheilion (lip corner at rest) along an imaginary line connecting the cheilion to the ipsilateral condylion (palpable when the jaw is moved) (Fig. 1A). Anodal stimulation was applied for $20 \mathrm{~min}$, at $1.5 \mathrm{~mA}$ intensity, over medialfrontal cortex (site FCz, from the International 10-20 System). The duration, intensity, and direction of current flow that we used has been shown to effectively enhance the performance of healthy subjects, as well as increase the amplitude of specific event-related potential waveforms (Reinhart and Woodman, 2015a). Comparable stimulation protocols have been shown to create an excitatory (anodal) effect lasting up to $5 \mathrm{~h}$ (Reinhart and Woodman, 2014). We always allowed at least $48 \mathrm{~h}$ between testing days to avoid carryover effects from the previous brain stimulation exposure (Monte-Silva et al., 2013).

Each subject completed two stimulation conditions, anodal and a sham control, on different days. The order of the conditions was randomized across subjects. The sham tDCS condition followed the same procedure as the anodal tDCS in which stimulation was delivered for 20 min, but stimulation only lasted $30 \mathrm{~s}$, ramping up and down at the beginning, middle, and end of the $20 \mathrm{~min}$ period, resulting in the same tingling and itching sensations associated with active tDCS. Debriefing questions confirmed that subjects were blind to the presence of stimulation. In addition, all subjects confirmed experiencing a mild tingling or itching sensation during the sham condition. To rule out potential con- founding factors related to the order in which stimulation was presented, we examined whether stimulation order (i.e., anodal followed by sham vs sham followed by anodal) was introducing bias and having a hidden effect on our dependent variables. We found no effect of stimulation order on ERN amplitude, RT, or accuracy $(F<1.122, p>0.304)$, demonstrating the effectiveness of the order randomization method we used across subjects.

Electroencephalography. We recorded the electroencephalogram (EEG) with an amplifier from SA Instrumentation and using a 0.01-100 $\mathrm{Hz}$ bandpass filter. We used nonpolarizable tin electrodes embedded in an elastic cap (Electrocap International). The electrodes were positioned based on the International 10-20 System $(\mathrm{Fz}, \mathrm{Cz}, \mathrm{Pz}, \mathrm{F} 3 / \mathrm{F} 4, \mathrm{C} 3 / \mathrm{C} 4$, $\mathrm{P} 3 / \mathrm{P} 4, \mathrm{PO} 3 / \mathrm{PO} 4, \mathrm{~T} 3 / \mathrm{T} 4, \mathrm{~T} 5 / \mathrm{T} 6, \mathrm{O} 1 / \mathrm{O} 2)$ and included 2 nonstandard sites (OL, midway between $\mathrm{O} 1$ and $\mathrm{T} 5$; and $\mathrm{OR}$, midway between $\mathrm{O} 2$ and T6). Signals were referenced online to the right mastoid electrode and sampled at $250 \mathrm{~Hz}$. Signals were then rereferenced offline to the average of the left and the right mastoids (Nunez and Srinivasan, 2006).

Horizontal eye position was monitored by recording electrooculogram from bipolar electrodes placed at the outer canthi of each eye. Vertical eye position and blinks were monitored with bipolar electrodes placed above and below the left orbit. Periorbital electrodes detected eye movements and a two-step ocular artifact rejection method was used. Individual trials were excluded from analyses and subjects were excluded if too many trials $(>25 \%)$ were lost or their averaged horizontal electrooculogram exhibited any deviations $>3 \mu \mathrm{V}$ (Woodman and Luck, 2003). The average rejection of trials during the learning period of the task (i.e., the first 50 trials from the start of the experiment) was $19.2 \%$ for patients and $11.4 \%$ for healthy controls.

Data analysis. For the ERN analyses, the continuous EEG data were time-locked to the button-press onset, and baseline corrected to the interval from 200 to $50 \mathrm{~ms}$ before response (Gehring et al., 2012). The ERN amplitude was measured from the central midline electrode (i.e., $\mathrm{Cz}$ ) using a time window from -50 to $150 \mathrm{~ms}$ relative to the response onset. We calculated amplitude of the voltages as the mean of the difference wave subtracting error trials from correct trials (Gehring et al., 2012). All statistical analyses were performed on unfiltered data. Of note, we were unable to measure the feedback-related negativity due to excessive $(>3 \mu \mathrm{V})$ electro-oculogram activity following feedback stimuli on $>30 \%$ of all trials in patients with schizophrenia. However, unlike the ERN, the feedback-related negativity is not consistently impaired in schizophrenia (Morris et al., 2008). Indeed, some studies have shown that the feedback-related negativity is fully intact in patients relative to healthy comparison subjects (Morris et al., 2011).

Current-flow model. We used our standard procedures for generating a forward model of tDCS current flow previously described in detail (Reinhart and Woodman, 2015a) and grounded in established methods (De Lucia et al., 2007; Wagner et al., 2007; Sadleir et al., 2010; Bikson et al., 2012). Constructing the model involved the following: (1) MRI segmentation, (2) electrode placement, (3) generation of a finite element model, and (4) computation. We used the MNI T1-weighted MRI reference brain from the CURRY 6.0 multimodal neuroimaging software (Compumedics Neuroscan). A combination of automated and manual segmentation tools was used to obtain tissue masks, including Gaussian filters, and morphological and Boolean operations implemented in MATLAB (The MathWorks). We used realistic volumetric head geometries with a numerical solver finite element method to better capture realistic sulci and gyri anatomy of the cortical surface, improving the overall accuracy of the model solution. Volumetric mesh was generated from the segmented data $(>140,000$ vertices, $>800,000$ tetrahedral elements). Segmented compartments and their respective isotropic electrical conductivities (in $\mathrm{S} / \mathrm{m}$ ) included the following: skin (0.33), skull (0.0042), and brain (0.33). The production of meshes involved dividing each mask into small contiguous elements, which allowed us to then numerically calculate the current flow.

The forward computation using a finite element model was implemented in SCIRun (available as open source software: http://software.sci.utah.edu). We simulated current flow with a bipolar electrode configuration, including the anode $\left(19.25 \mathrm{~cm}^{2}\right)$ centered over FCz and the cathode $\left(52 \mathrm{~cm}^{2}\right)$ centered over the right cheek between the zygomaticus major and the condylion. Current density 

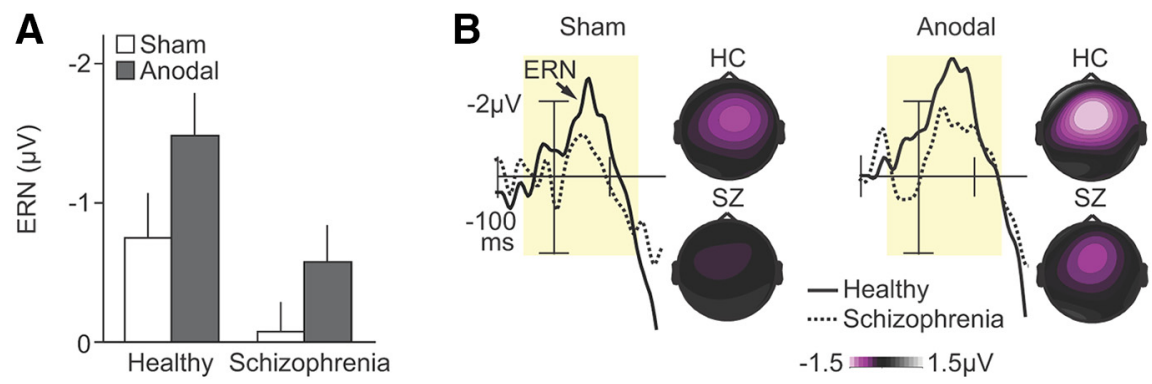

C

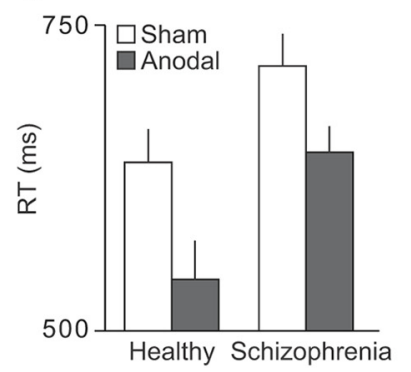

D

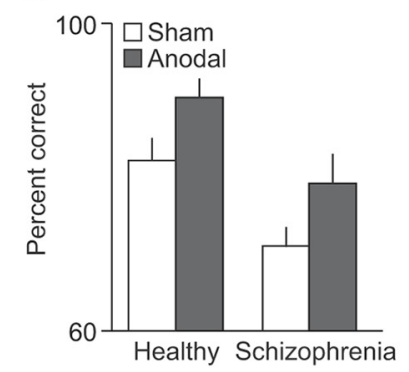

Figure 2. Strengthening prediction error electrophysiology and behavior in schizophrenia using electrical stimulation over medial-frontal cortex. A, Mean ERN amplitude shown across healthy controls (HC) and patients with schizophrenia (SZ) for sham (white) and anodal (gray) stimulation conditions. $\boldsymbol{B}$, Response-synchronized difference waves (i.e., the ERN) derived from errorminus-correct trials shown at central midline electrode sites (Cz) across subject groups (solid line indicates controls; dotted line indicates patients) and stimulation conditions. Topographical maps represent the spatial distribution of the ERN, based on the -50 to 150 ms periresponse analytic window (pale yellow shading) of the error-minus-correct difference waves. $C$, Mean RT shown across subject groups and stimulation conditions. D, Mean percentage correct accuracy shown across subject groups and stimulation conditions. Error bars indicate \pm 1 SEM.

corresponding to $1.5 \mathrm{~mA}$ total current was applied at the anodal electrode, and ground was applied at the cathodal electrode.

To determine the distribution of electrical potential inside the human tissues, the Laplace equation:

$$
\vec{\nabla} \cdot(\sigma \vec{\nabla} \varphi)=0
$$

( $\varphi$, potential; $\sigma$, conductivity) was solved, and the following boundary conditions were used. Inward current flow $=\mathrm{J}_{\mathrm{n}}$ (normal current density) was applied to the exposed surface of the anode. The ground was applied to the exposed surface of the cathode. All other external surfaces were treated as insulated. Plots show the cortical current density distribution (Fig. 1A). It is important to emphasize that our tDCS modeling solution is not intended as a strong claim about the exact location of current flow during stimulation. Rather, our model serves as a working hypothesis for where the trajectory of electrical field passes through the brain given our specific tDCS montage. In addition, this model offers researchers potential target locations for future investigation into prediction error processing using techniques, such as human neuroimaging or animal neurophysiology.

Statistical analysis. Analyses were focused on the first 50 trials of the experiment in which subjects learned the stimulus-response mapping assignment for the day. We used mixed-model ANOVAs with the between-subjects factor of group (patients vs controls), and the withinsubjects factors of stimulation (anodal vs sham), and time (bin 1 vs bin 2 vs bin 3 vs bin 4 vs bin 5). Separate bin-wise analyses were performed for each dependent variable of RT, accuracy (in percentage correct), and ERN amplitudes averaged into 5 bins of 10 trials each (i.e., bin 1 contained trials $1-10$, bin 2 contained trials $11-20$, etc.). We specifically chose an average bin size of 10 trials to generate ERNs with good signalto-noise ratios, given previous work showing that 6 trials is sufficient to accurately quantify a stable and reliable response-locked ERN (Pontifex et al., 2010). More importantly, the 10-trial wide analysis bins allowed us to model the evolution of the error potentials (i.e., the ERNs) during learning, consistent with previously established methods (Holroyd and Coles, 2002; Reinhart and Woodman, 2014), most notably the seminal

work by Holroyd and Coles (2002) on the reinforcement learning theory of the ERN. Interactions were parsed with follow-up ANOVAs where appropriate. We adjusted $p$ values using the Greenhouse-Geisser $\varepsilon$ correction for nonsphericity when the sphericity assumption was violated (Jennings and Wood, 1976).

\section{Results}

Our results from patients with schizophrenia at baseline are consistent with the hypothesized impairment in learning dependent on prediction error signaling. Figure 2 shows the neural and behavioral events related to learning during the period of the experiment in which subjects were determining the optimal response strategy of the task.

We observed no measurable ERN in patients (error vs correct trials, $F_{(1,17)}=$ 1.052, $p=0.319$ ) and reduced ERN amplitude in patients relative to controls $\left(F_{(1,17)}=4.916, p=0.041\right)$ (Fig. $\left.2 A, B\right)$. The behavioral changes in the patients largely mirrored the ERN impairments we observed, and provided further evidence for impaired prediction error calculations in the brains of patients. Specifically, patients were dramatically slower to respond $\left(F_{(1,17)}=10.099, p=0.006\right)$ and less accurate $\left(F_{(1,17)}=27.241, p>0.001\right)$ compared with controls (Fig. 2C,D). These behavioral results from the sham condition show that patients with schizophrenia struggled to learn rapidly from their mistakes. By recording subjects' event-related potentials, we demonstrated that the inability of patients to rapidly learn a new task was due, in part, to disrupted error-related electrophysiology, consistent with the hypothesis that abnormal prediction error signaling in schizophrenia underlies the dysfunctional use of errors to improve future decisions.

If medial-frontal brain regions play a critical role in learning driven by prediction error signaling, the electrical stimulation of these regions should augment the neural and behavioral events associated with this learning. Figure 2 shows that anodal tDCS over medial-frontal cortex had a strong positive effect on the neural and behavioral indices of learning. First, for patients, anodal stimulation boosted ERN amplitude (error vs correct trials, $\left.F_{(1,17)}=6.509, p=0.021\right)$, leading to a significantly larger ERN after stimulation relative to the sham $\left(F_{(1,17)}=4.494, p=0.049\right)$ (Fig. 2A,B). Similarly, for controls, the ERN was larger following stimulation $\left(F_{(1,17)}=4.968, p=0.040\right)$. However, there was no group difference in the stimulation-induced ERN enhancements (stimulation $\times$ group interaction, $F_{(1,17)}=0.871, p=0.364$ ) (for an explanation of this finding, see Discussion). Second, the impact of medial-frontal tDCS on subjects' behavior showed a tight correspondence with the effects we observed on the error-related electrophysiology. There were sizable improvements in behavior following stimulation in the patients $\left(\mathrm{RT}, F_{(1,17)}=8.467, p=\right.$ 0.010 ; accuracy, $\left.F_{(1,17)}=10.850, p=0.004\right)$ and controls $\left(\mathrm{RT}, F_{(1,17)}=10.182, p=0.005\right.$; accuracy $F_{(1,17)}=17.892, p=$ $0.001)$, with no stimulation $\times$ group interaction on $\operatorname{RT}\left(F_{(1,17)}=\right.$ $1.315, p=0.267)$ or accuracy $\left(F_{(1,17)}=0.091, p=0.767\right)$ (Fig. $2 C, D)$. Third, the anodal stimulation eliminated the significant 
between-group differences we observed at baseline, such that patients in the anodal condition were quantitatively indistinguishable from controls in the sham condition in terms of ERN amplitude $\left(F_{(1,17)}\right.$ $=2.432, p=0.137)$, $\mathrm{RT}\left(F_{(1,17)}=0.477\right.$, $p=0.499)$, and accuracy $\left(F_{(1,17)}=2.833\right.$, $p=0.111)$. These results show that medial-frontal tDCS can induce lasting effects on the ERN and learning. Further, the beneficial effects induced by anodal stimulation in the patients were sufficient to temporarily equate the ERN and the learning rates between the patients and the healthy individuals at baseline.

We obtained similar results when calculating peak ERN amplitudes in patients based solely on error-trial data, with the potentials measured from -50 to $150 \mathrm{~ms}$ periresponse. The similarity included the group $\times$ time interaction on ERN amplitude $\left(F_{(4,136)}=4.451\right.$, $p=0.004)$, the stimulation $\times$ time interaction on ERN amplitude in patients $\left(F_{(4,68)}=5.677, p=0.005\right)$, and the effect of the mean rate parameters of the ERN amplitudes between stimulation conditions in patients $\left(t_{(34)}=4.179, p<0.01\right)$. Thus, our findings regarding the ERN generalize to multiple measures of this component.

The results presented in Figure 2 provide evidence for a causal link between aberrant prediction error signaling over medial-frontal cortex and learning deficits in schizophrenia. However, to examine the neural and behavioral dynamics of learning, we performed a more precise quantification of our dependent variables, charting their evolution over the course of learning. Specifically, we sorted the data into 10 trial-wide bins from the start of the experiment, consistent with fundamental work on reinforcement learning theory of the ERN (Holroyd and Coles, 2002) (for details, see Materials and Methods). Importantly, reducing the bin size allowed us to model the neural and behavioral dynamics as learning progressed in the task, and to test the prediction of this learning theory of the ERN in patients with schizophrenia that when the ERN is abnormal, learning should also be abnormal.

The findings at baseline (i.e., the sham condition) support the view that patients with schizophrenia exhibit dysfunctional prediction error signaling dynamics during learning. First, the ERNs from patients in the sham condition were severely blunted across learning trials relative to controls (Fig. 3 ). This was confirmed statistically by the absence of a main effect of time on ERN amplitude in patients $\left(F_{(4,68)}=0.644\right.$, $p=0.577)$, and a significant group $\times$ time interaction on ERN amplitude $\left(F_{(4,136)}=4.898, p=0.002\right)$. Second, we observed that learning in patients was impaired in the sham condition (Fig. 3). Behavioral gains associated with learning were reduced in patients relative to controls, evidenced by significant interactions of group $\times$ time on $\operatorname{RT}\left(F_{(4,136)}=3.909, p=\right.$ $0.008)$ and accuracy $\left(F_{(4,136)}=3.725, p=0.045\right)$.

Figure 3 shows that anodal stimulation in patients transformed their ERN amplitude function during learning and caused their rates of learning to accelerate, matching those of healthy controls in the sham condition. These observations were supported by interactions of stimulation $\times$ time on ERN amplitude $\left(F_{(4,68)}=6.592, p=0.001\right)$ and $\operatorname{RT~}\left(F_{(4,36)}=6.438\right.$, $p=0.003)$, with accuracy also at a trend level $\left(F_{(4,68)}=2.484\right.$, $p=0.079)$ in the patients. The latter accuracy result was likely due to the extent of behavioral learning exhibited by patients in the sham condition (for a detailed explanation, see Discussion). Moreover, we obtained similar findings when controlling for trial number differences between time bins. That is, because learning inevitably involves improvements in accuracy, the ERNs produced across learning involve progressively fewer error trials. Thus, to rule out the alternative hypothesis that trial number differences accounted for the ERN changes during learning, we randomly selected error trials to exclude from the more heavily represented bins until no significant differences were present in the trial numbers across time bins $1-5$. The critical interaction of stimulation $\times$ time on ERN amplitude remained significant $\left(F_{(4,68)}=4.535, p=\right.$ $0.010)$, strengthening the conclusion that medial-frontal stimulation improved prediction error signaling and learning rates in patients with schizophrenia.

Next, by modeling these learning data with a logarithmic function (Logan, 1988), we found that anodal stimulation relative to sham increased the mean rate parameters of the ERN $\left(t_{(34)}=5.352, p<0.01\right)$, RT $\left(t_{(34)}=3.616, p=0.01\right)$, and accu$\operatorname{racy}\left(t_{(34)}=2.128, p=0.041\right)$ in patients. These findings mirror results obtained using Rescorla-Wagner reinforcement-learning models to track the development of certainty over the course of a probabilistic learning task in healthy adults (Klein et al., 2007). Most important, the significant differences in learning dynamics between patients and controls observed at baseline were no longer present after patients received anodal stimulation (ERN $F_{(4,68)}=1.218, p=0.309$, RT $F_{(4,68)}=2.113, p=0.116$, accuracy $\left.F_{(4,68)}=0.720, p=0.536\right)$ compared with the controls in the sham baseline. This suggests that $20 \mathrm{~min}$ of stimulation to medial-frontal cortex was sufficient to elevate patients with schizophrenia to the functioning of their healthy control counterparts in terms of neural prediction error signaling and behavioral signatures of learning speed.

To determine the effectiveness of the brain stimulation protocol to strengthen prediction error signaling and learning in schizophrenia, we examined the differences in each subject's learning rate data across stimulation conditions. We found that the majority of patients and controls exhibited clear stimulationinduced improvements during learning. This was shown by significantly faster growth rates of ERN amplitude, RT, and accuracy in patients ( 13 of 17 , each $t>2.357, p<0.031$ ) and controls ( 15 of 18 , each $t>2.486, p<0.024$ ) after anodal tDCS relative to sham. These results demonstrate the reliability of medial-frontal stimulation to enhance prediction error signaling in the brain and learning rate in the individual. 
Table 2. Correlational analysis ${ }^{a}$

\begin{tabular}{|c|c|c|c|c|}
\hline & \multicolumn{2}{|c|}{ Sham ERN } & \multicolumn{2}{|c|}{ tDCS-induced $\Delta$ ERN } \\
\hline & $R$ & $p$ & $R$ & $p$ \\
\hline Illness duration & 0.093 & 0.714 & 0.256 & 0.304 \\
\hline SAPS & -0.031 & 0.902 & 0.035 & 0.892 \\
\hline Hallucinations & -0.296 & 0.233 & -0.175 & 0.488 \\
\hline Bizarre behavior & -0.018 & 0.944 & -0.274 & 0.271 \\
\hline Delusions & 0.157 & 0.535 & -0.804 & $0.00005^{*}$ \\
\hline Positive formal TD & -0.043 & 0.864 & 0.078 & 0.757 \\
\hline SANS & -0.740 & $0.0004^{*}$ & -0.174 & 0.490 \\
\hline Affective flattening & -0.657 & $0.003^{*}$ & -0.150 & 0.552 \\
\hline Alogia & -0.424 & 0.080 & 0.074 & 0.770 \\
\hline Avolition apathy & -0.137 & 0.589 & -0.128 & 0.612 \\
\hline Anhedonia asociality & -0.495 & $0.037^{*}$ & -0.330 & 0.182 \\
\hline Attention & -0.277 & 0.265 & 0.077 & 0.762 \\
\hline BPRS & -0.288 & 0.246 & -0.214 & 0.393 \\
\hline
\end{tabular}

${ }^{a}$ The two-tailed Pearson correlation results show the brain-symptom relationship between individual patient ERN learning rates, and clinical symptom scores and illness duration. Learning rate parameters were taken from logarithmic model fits based on ERN amplitude dynamics during learning in the sham, baseline condition (left columns), and the change in ERN amplitude dynamics during learning from sham to anodal conditions (right columns). TD, thought disorder.

*Significant.

If prediction error signaling dysfunction is a central feature in the pathophysiology of schizophrenia, then we should be able to determine significant relationships between prediction error signaling and the clinical symptoms in schizophrenia. Models of schizophrenia propose that the primary impairment in the illness is a disruption of prediction error signaling related to dopamine (Corlett et al., 2006, 2007; Frank, 2008; Fletcher and Frith, 2009; Waltz et al., 2009), leading to behavioral motivation based on faulty associations and contingencies (Kapur, 2003; Smith et al., 2006). The ERN has been linked to reward processing, dopamine, and the computation of prediction error (Goldman-Rakic, 1999; Holroyd and Coles, 2002). Consistent with these hypotheses, our results at baseline show that patients exhibited abnormal ERN amplitude during the learning task (see Figs. 2, 3). But these hypotheses also predict that ERN abnormalities during learning in schizophrenia should be related to negative clinical symptoms, such as impairments in motivation and anhedonia (Morris et al., 2011; Mathalon and Ford, 2012; but see Mathalon et al., 2002).

We found that negative symptom severity predicted the abnormal ERN amplitude changes across learning in patients with schizophrenia during the baseline condition. Table 2 shows the two-tailed, Pearson correlation results from comparing the learning rate parameters of ERN amplitude in the sham condition against each measure of clinical symptoms and illness duration. The total score on the SANS $\left(R_{(17)}=-0.740, p=0.0004\right)$ and the individual scores for the negative symptom of affective flattening $\left(R_{(17)}=-0.657, p=0.003\right)$ and anhedonia asociality $\left(R_{(17)}=-0.495, p=0.037\right)$ show that patients with the highest levels of negative symptoms showed the lowest rates of growth in ERN amplitude (i.e., less negative potential between error and correct trials across learning) (Fig. 4A-C). The ERN-SANS correlation remained significant after correcting for multiple comparisons using the Benjamini-Hochberg correction procedure (Benjamini and Hochberg, 1995) with a false discovery rate as low as $5 \%$. This pattern of findings is consistent with evidence of poor internal representation of motivational information (Ursu et al., 2011) and disruption of prediction error computation (Krawitz et al., 2011) in schizophrenia. Patients with strong negative symptoms likely suffer from selective impairments in motivation to seek out rewarding activities (Gold et al., 2012). Our results suggest that the putative index of reward prediction error signaling (i.e., the ERN) is sensitive to selective motivational impairments in schizophrenia.
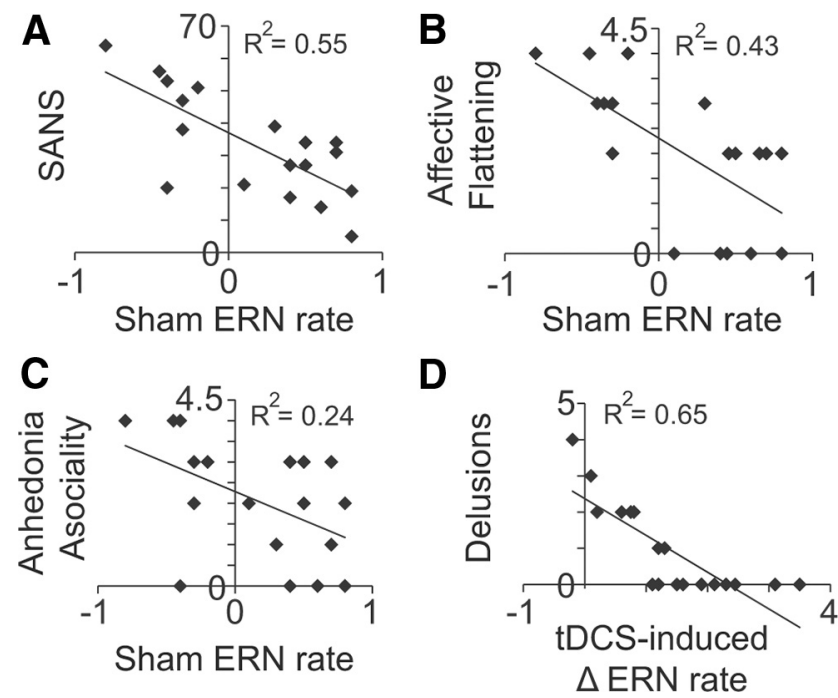

Figure 4. Brain-symptom relationships. Scatter plots represent the relationships between individual patient ERN learning rates and the total score on the SANS $(\boldsymbol{A})$, and the individual scores for affective flattening $(\boldsymbol{B})$, alogia $(\boldsymbol{C})$, and delusions $(\boldsymbol{D})$. Learning rate parameters were taken from logarithmic model fits based on ERN amplitude dynamics during learning in the sham, baseline condition ( $\boldsymbol{A}-\boldsymbol{C}$ ) or the change in ERN amplitude dynamics during learning from sham to anodal conditions (D).

Figure $4 A-C$ provides evidence for brain-symptom relationships important to our understanding of the etiology of schizophrenia. However, it is also critical to understand whether certain clinical symptoms of schizophrenia predispose a patient to the benefits of our electrical brain stimulation regimen. Accordingly, we asked whether patients' clinical data collected at baseline could predict the effectiveness of the medial-frontal tDCS. We correlated each patient's tDCS-induced ERN modulation (i.e., anodal-minus-sham logarithmic learning rate values) with their data on illness duration, individual clinical symptoms, and total clinical symptom scores. As shown in Table 2, we found that patients with the sharpest rates of growth in ERN amplitudes following stimulation were those with the lowest level of positive symptoms scores for delusions $\left(R_{(17)}=-0.804, p=0.00005\right)$ (Fig. $4 D$ ). This correlation remained significant after correcting for multiple comparisons using a false discovery rate of $1 \%$. The clinical ratings were obtained for each patient before study participation. As a result, we could not determine the causal effects of tDCS on the specific symptoms, such as whether anodal stimulation caused an amelioration of delusions in patients. However, the strong negative relationship between delusions at baseline and the later tDCS-induced ERN enhancements during learning does suggest important information about individual differences in patients' delusions and the effectiveness of the medial-frontal stimulation protocol that we have developed to boost prediction error signaling and learning rate.

To rule out the possibility that the patterns of effects observed in the patients were due to antipsychotic medications, we examined whether any of our dependent measures varied as a function of medication dose. We calculated chlorpromazine (CPZ) equivalent dosages for all patients and correlated it with ERN amplitude, RT, and accuracy across the learning period of the task for the sham and anodal stimulation conditions. We found that CPZ dose was not associated with any of the dependent measures (all $r<0.307, p>0.231$ ). These findings are consistent with previous reports showing that antipsychotic medication leads to mild improvement in cognitive symptoms of schizophrenia (Keefe et al., 
2007), instead of being the source of the impairments in patients. Of note, CPZ equivalent dose is associated with dopamine receptor binding, which is particularly relevant for the study of prediction error signaling, given the links between the brain's computation of prediction error and dopamine (Schultz and Dickinson, 2000), and ERN amplitude and dopamine (Holroyd and Coles, 2002; Jocham and Ullsperger, 2009; Gehring et al., 2012).

\section{Discussion}

In this study, we demonstrated the effectiveness of noninvasive brain stimulation targeting medial-frontal cortex to boost prediction error signaling in patients with schizophrenia. This manipulation enabled patients to more effectively learn from their mistakes. At baseline, the patients' learning was severely impaired, consistent with work showing degraded frontocortical circuitry (Dolan et al., 1995; Sanders et al., 2002) and abnormal prediction error signaling (Corlett et al., 2007; Murray et al., 2008; Fletcher and Frith, 2009) in schizophrenia. However, after $20 \mathrm{~min}$ of electrical stimulation over these compromised frontal regions, we were able to temporarily normalize the ERN measure of prediction error signaling and learning rate in our laboratory task.

It might seem counterintuitive that, at baseline, patients with schizophrenia showed some evidence of learning as measured with behavior, albeit slowed, without a corresponding increase in ERN amplitude across the same experimental trials (Fig. 2), given the putative role of the ERN in learning (Holroyd and Coles, 2002). However, theories of the ERN and learning (Barto, 1995; Houk et al., 1995; Brown et al., 1999; Holroyd and Coles, 2002; Yin and Knowlton, 2006) propose that the midbrain dopamine system generates the prediction error signal, conveying information to the basal ganglia and frontal cortex. Once in frontal cortex, the prediction error signal is used by anterior cingulate cortex to facilitate the development of adaptive motor programs. It is at this relatively late stage of information processing underlying learning that ERN production is hypothesized to occur (Holroyd and Coles, 2002). The present findings are consistent with the idea that the ERN represents neural processes occurring downstream from the subcortical effects that drive much of the improvement in task performance in the laboratory, with the prediction error signal of the ERN used to further tune stimulusresponse mappings at the cortical level. Thus, the differential effects of subject group on ERN and learning behavior at baseline are not only unsurprising but also suggest several testable hypotheses regarding the source of prediction error signals in the human brain. Future work will be needed to further test the hypothesis that the computations of value by the adaptive critic implemented by the basal ganglia are to some extent functionally intact in schizophrenia, as the behavioral evidence of learning from our patients at baseline indicates.

Although it is clear that some amount of learning is possible when a minimal ERN is concurrently measured, the most striking results of the present study were those showing that medialfrontal stimulation caused significant enhancements of the ERN and learning rate in patients with schizophrenia. These findings can be interpreted with respect to the known striocortical loops involved in learning. The striosome compartments in the basal ganglia constitute the main input into the midbrain dopamine system (Graybiel et al., 1994; Graybiel and Kimura, 1995) and comprise the substrate for temporal difference error computation (Barto, 1995; Houk et al., 1995; Brown et al., 1999; Holroyd and Coles, 2002). The only cortical regions with robust projections to the striosomes come from the caudal orbitofrontal ante- rior insular cortex and the medial-frontal prelimbic anterior cingulate cortex (Eblen and Graybiel, 1995). Thus, anterior cingulate activity can influence the midbrain dopamine system, which can then form an iterative loop to drive activity in anterior cingulate cortex and other areas. This corticostriatal loop idea is important because it helps explain how our medial-frontal stimulation might have indirectly influenced the midbrain system (e.g., producing greater dopaminergic disinhibition) by first modulating medial-frontal areas, such as anterior cingulate cortex.

There are several lines of evidence supporting the interpretation that the medial-frontal stimulation we used here modulated synaptic transmission in the corticostriatal loop involving the midbrain dopamine system and regions of medial-frontal cortex. First, it is widely recognized that tDCS is a method for guiding neuroplasticity, including synaptic plasticity, and modulating cortical functions of the brain (Nitsche et al., 2008). Second, animal work has shown that electrical stimulation of the medialprefrontal cortex and the anterior cingulate cortex can cause bursting activity in midbrain dopamine cells (Gariano and Groves, 1988; Tong et al., 1996). Third, evidence from computational modeling (Servan-Schreiber et al., 1990) and neurophysiology (Yang and Seamans, 1996) has shown that the strength of dopaminergic input into the prefrontal cortex can change the gain of synaptic transmission in prefrontal cortex. That is, a lowering of dopaminergic input to the apical dendrites of Layer $\mathrm{V}$ pyramidal cells reduces the gain of the pyramidal cell, which permits a broader range of input to drive the cell (Yang and Seamans, 1996). Interestingly, these are precisely the neurophysiological events hypothesized to underlie ERN generation (Holroyd and Coles, 2002; Gehring et al., 2012). In the case of anodal stimulation, it seems likely that the medial-frontal tDCS caused a rapid reduction in gain on error trials, allowing the anterior cingulate cortex to perform a more efficient search for an optimal motor controller over a larger range of controller inputs. However, it is also possible that anodal stimulation boosted gain on error trials, yielding improvements in learning behavior through more confident predictions, thus producing larger prediction error signal expressed as higher-amplitude ERNs. These hypotheses are not mutually exclusive. The flexibility of motor selection and the confidence in predictions may be simultaneously enhanced by tDCS. Moreover, the dopaminergic changes following tDCS may depend on the starting point of the individual and follow an inverted U-shaped function, in which some individuals are pushed further up the curve toward a more optimal state, whereas higher performers are pushed down. Additional research will be useful for clarifying the relevance of this corticostriatal loop for the medial-frontal stimulation effects we observed.

Our results are consistent with the view that patients with schizophrenia and healthy individuals exist along a wellness spectrum and do not differ categorically from one another (Raine, 2006; Modinos et al., 2010; Woodward et al., 2011; Choi et al., 2012). We found that the medial-frontal tDCS resulted in a similar enhancement of the ERN and learning rate in patients with schizophrenia and healthy subjects. As evidence for a continuum view, we found no stimulation $\times$ group interactions throughout our analyses, exactly as predicted if the nature of the mechanisms implementing prediction error signaling and learning were not qualitatively different across patients and controls. This continuum view to understanding schizophrenia symptoms is consistent with the principles of the National Institute of Mental Health research domain criteria (Insel et al., 2010).

Our results add to the progress on brain-symptom relationships in clinical science. Over the last half century, efforts to understand 
the etiology of schizophrenia have been dominated by research focused on the neurobiological bases of the clinical heterogeneity of the disorder. However, establishing brain-symptom correlations has been a challenge due to a variety of factors, including underpowered samples, measurements with low reliability and validity, medication confounds, and correlation-causation uncertainty. Here, we worked to minimize these conceptual and methodological obstacles by performing power analyses (see Materials and Methods), using one of the most reliably documented electrophysiological abnormalities in schizophrenia (i.e., the ERN) (Gehring et al., 2012), ruling out the possibility of antipsychotic medication confounds (see Materials and Methods), and using a causal neuroscientific technique. As a result, we found that negative symptom severity predicted faulty prediction error signaling as measured by reductions in ERN learning dynamics at baseline, consistent with previous work (Morris et al., 2011; Mathalon and Ford, 2012; but see Mathalon et al., 2002). Additionally, we report, for the first time, that the severity of psychotic delusions may exclude such patients from fully experiencing the positive cognitive benefits of medial-frontal stimulation. This result provides critical information for translational scientists focused on optimizing tDCS protocols for cognitive enhancement in individual patients.

\section{References}

Alexander WH, Brown JW (2011) Medial prefrontal cortex as an actionoutcome predictor. Nat Neurosci 14:1338-1344. CrossRef Medline

Andreasen NC (1983) The Scale for the Assessment of Negative Symptoms (SANS). Iowa City, IA: University of Iowa.

Andreasen NC (1984) The Scale for the Assessment of Positive Symptoms (SAPS). Iowa City, IA: University of Iowa.

Barto AG (1995) Adaptive critics and the basal ganglia. In: Models of information processing in the basal ganglia (Houk J, Davis J, Beiser D, eds), pp 215-232. Cambridge, MA: Massachusetts Institute of Technology.

Bates AT, Kiehl KA, Laurens KR, Liddle PF (2002) Error-related negativity and correct response negativity in schizophrenia. Clin Neurophysiol 113: 1454-1463. CrossRef Medline

Behrens TE, Woolrich MW, Walton ME, Rushworth MF (2007) Learning the value of information in an uncertain world. Nat Neurosci 10:12141221. CrossRef Medline

Benjamini Y, Hochberg Y (1995) Controlling the false discovery rate: a practical and powerful approach to multiple testing. J R Stat Soc B 57:289-300.

Bikson M, Rahman A, Datta A (2012) Computational models of transcranial direct current stimulation. Clin EEG Neurosci 43:176-183. CrossRef Medline

Brown JW, Braver TS (2005) Learned predictions of error likelihood in the anterior cingulate cortex. Science 307:1118-1121. CrossRef Medline

Brown J, Bullock D, Grossberg S (1999) How the basal ganglia use parallel excitatory and inhibitory learning pathways to selectively respond to unexpected rewarding cues. J Neurosci 19:10502-10511. Medline

Choi JS, Park JY, Jung MH, Jang JH, Kang DH, Jung WH, Han JY, Choi CH, Hong KS, Kwon JS (2012) Phase-specific brain change of spatial working memory processing in genetic and ultra-high risk groups of schizophrenia. Schizophr Bull 38:1189-1199. CrossRef Medline

Corlett PR, Fletcher PC (2012) The neurobiology of schizotypy: frontostriatal prediction error signal correlates with delusion-like beliefs in healthy people. Neuropsychologia 50:3612-3620. CrossRef Medline

Corlett PR, Honey GD, Aitken MR, Dickinson A, Shanks DR, Absalom AR, Lee M, Pomarol-Clotet E, Murray GK, McKenna PJ, Robbins TW, Bullmore ET, Fletcher PC (2006) Frontal responses during learning predict vulnerability to the psychotogenic effects of ketamine: linking cognition, brain activity, and psychosis. Arch Gen Psychiatry 63:611-621. CrossRef Medline

Corlett PR, Murray GK, Honey GD, Aitken MR, Shanks DR, Robbins TW, Bullmore ET, Dickinson A, Fletcher PC (2007) Disrupted prediction error signal in psychosis: evidence for an associative account of delusions. Brain 130:2387-2400. CrossRef Medline

Corlett PR, Taylor JR, Wang XJ, Fletcher PC, Krystal JH (2010) Toward a neurobiology of delusions. Prog Neurobiol 92:345-369. CrossRef Medline
De Lucia M, Parker GJ, Embleton K, Newton JM, Walsh V (2007) Diffusion tensor MRI-based estimation of the influence of brain tissue anisotropy on the effects of transcranial magnetic stimulation. Neuroimage 36:11591170. CrossRef Medline

Dolan RJ, Fletcher P, Frith CD, Friston KJ, Frackowiak RS, Grasby PM (1995) Dopaminergic modulation of impaired cognitive activation in the anterior cingulate cortex in schizophrenia. Nature 378:180-182. CrossRef Medline

Eblen F, Graybiel AM (1995) Highly restricted origin of prefrontal cortical inputs to striosomes in the macaque monkey. J Neurosci 15:5999-6013. Medline

First MB, Spitzer RL, Gibbon M, Williams JBW (1995) Structured Clinical Interview for DSM-IV Axis I Disorders: New York: Biometrics Research Department, NY State Psychiatric Institute.

Fletcher PC, Frith CD (2009) Perceiving is believing: a Bayesian approach to explaining the positive symptoms of schizophrenia. Nat Rev Neurosci 10:48-58. CrossRef Medline

Foti D, Kotov R, Bromet E, Hajcak G (2012) Beyond the broken errorrelated negativity: functional and diagnostic correlates of error processing in psychosis. Biol Psychiatry 71:864-872. CrossRef Medline

Frank MJ (2008) Schizophrenia: a computational reinforcement learning perspective. Schizophr Bull 34:1008-1011. CrossRef Medline

Frank MJ, Woroch BS, Curran T (2005) Error-related negativity predicts reinforcement learning and conflict biases. Neuron 47:495-501. CrossRef Medline

Gariano RF, Groves PM (1988) Burst firing induced in midbrain dopamine neurons by stimulation of the medial prefrontal and anterior cingulate cortices. Brain Res 462:194-198. CrossRef Medline

Gehring WJ, Liu Y, Orr JM, Carp J (2012) The error-related negativity (ERN/Ne). In: Oxford handbook of event-related potential components (Luck SJ, Kappenman E, eds), pp 231-291. New York: Oxford UP.

Gold JM, Waltz JA, Matveeva TM, Kasanova Z, Strauss GP, Herbener ES, Collins AG, Frank MJ (2012) Negative symptoms in schizophrenia result from a failure to represent the expected value of rewards: behavioral and computational modeling evidence. Arch Gen Psychiatry 69:129-138. CrossRef Medline

Goldman-Rakic PS (1999) The physiological approach: functional architecture of working memory and disordered cognition in schizophrenia. Biol Psychiatry 46:650-661. CrossRef Medline

Graybiel AM, Kimura M (1995) Adaptive neural networks in the basal ganglia. In: Models of information processing in the basal ganglia (Houk J, Davis J, Beiser D, eds), pp 103-116. Cambridge, MA: Massachusetts Institute of Technology.

Graybiel AM, Aosaki T, Flaherty AW, Kimura M (1994) The basal ganglia and adaptive motor control. Science 265:1826-1831. CrossRef Medline

Haggard P (2008) Human volition: towards a neuroscience of will. Nat Rev Neurosci 9:934-946. CrossRef Medline

Hemsley DR (2005) The development of a cognitive model of schizophrenia: placing it in context. Neurosci Biobehav Rev 29:977-988. CrossRef Medline

Holroyd CB, Coles MG (2002) The neural basis of human error processing: reinforcement learning, dopamine, and the error-related negativity. Psychol Rev 109:679-709. CrossRef Medline

Houk JC, Adams JL, Barto AG (1995) A model of how the basal ganglia generate and use neural signals that predict reinforcement. In: Models of information processing in the basal ganglia (Houk J, Davis J, Beiser D, eds), pp 249-270. Cambridge, MA: Massachusetts Institute of Technology.

Insel T, Cuthbert B, Garvey M, Heinssen R, Pine DS, Quinn K, Sanislow C, Wang P (2010) Research domain criteria (RDoC): toward a new classification framework for research on mental disorders. Am J Psychiatry 167:748-751. CrossRef Medline

Jennings JR, Wood CC (1976) The e-adjustment procedure for repeatedmeasures analyses of variance. Psychophysiology 13:277-278. CrossRef Medline

Jocham G, Ullsperger M (2009) Neuropharmacology of performance monitoring. Neurosci Biobehav Rev 33:48-60. CrossRef Medline

Kapur S (2003) Psychosis as a state of aberrant salience: a framework linking biology, phenomenology, and pharmacology in schizophrenia. Am J Psychiatry 160:13-23. CrossRef Medline

Keefe RS, Bilder RM, Davis SM, Harvey PD, Palmer BW, Gold JM, Meltzer HY, Green MF, Capuano G, Stroup TS, McEvoy JP, Swartz MS, Rosenheck RA, Perkins DO, Davis CE, Hsiao JK, Lieberman JA (2007) Neu- 
rocognitive effects of antipsychotic medications in patients with chronic schizophrenia in the CATIE trial. Arch Gen Psychiatry 64:633-647. CrossRef Medline

Klein TA, Neumann J, Reuter M, Hennig J, von Cramon DY, Ullsperger M (2007) Genetically determined differences in learning from errors. Science 318:1642-1645. CrossRef Medline

Krawitz A, Braver TS, Barch DM, Brown JW (2011) Impaired errorlikelihood prediction in medial prefrontal cortex in schizophrenia. Neuroimage 54:1506-1517. CrossRef Medline

Logan GD (1988) Toward an instance theory of automatization. Psychol Rev 95:492-527. CrossRef

Mathalon DH, Ford JM (2012) Neurobiology of schizophrenia: search for the elusive correlation with symptoms. Front Hum Neurosci 6:136. CrossRef Medline

Mathalon DH, Fedor M, Faustman WO, Gray M, Askari N, Ford JM (2002) Response-monitoring dysfunction in schizophrenia: an event-related brain potential study. J Abnorm Psychol 111:22-41. CrossRef Medline

Matsumoto M, Matsumoto K, Abe H, Tanaka K (2007) Medial prefrontal cell activity signaling prediction errors of action values. Nat Neurosci 10:647-656. CrossRef Medline

Modinos G, Mechelli A, Ormel J, Groenewold NA, Aleman A, McGuire PK (2010) Schizotypy and brain structure: a voxel-based morphometry study. Psychol Med 40:1423-1431. CrossRef Medline

Monte-Silva K, Kuo MF, Hessenthaler S, Fresnoza S, Liebetanz D, Paulus W, Nitsche MA (2013) Induction of late LTP-like plasticity in the human motor cortex by repeated non-invasive brain stimulation. Brain Stimul 6:424-432. CrossRef Medline

Morris SE, Heerey EA, Gold JM, Holroyd CB (2008) Learning-related changes in brain activity following errors and performance feedback in schizophrenia. . Schizophr Res 99:274-285. CrossRef Medline

Morris SE, Holroyd CB, Mann-Wrobel MC, Gold JM (2011) Dissociation of response and feedback negativity in schizophrenia: electrophysiological and computational evidence for a deficit in the representation of value. Front Hum Neurosci 5:123. CrossRef Medline

Murray GK, Corlett PR, Clark L, Pessiglione M, Blackwell AD, Honey G, Jones PB, Bullmore ET, Robbins TW, Fletcher PC (2008) Substantia nigra/ventral tegmental reward prediction error disruption in psychosis. Mol Psychiatry 13:267-276. CrossRef Medline

Nitsche MA, Cohen LG, Wassermann EM, Priori A, Lang N, Antal A, Paulus W, Hummel F, Boggio PS, Fregni F, Pascual-Leone A (2008) Transcranial direct current stimulation: state of the art 2008. Brain Stimul 1:206223. CrossRef Medline

Nunez PL, Srinivasan R (2006) Electric fields of the brain: the neurophysics of EEG, Ed 2. Oxford: Oxford UP.

Overall JE, Gorham DR (1962) The brief psychiatric rating scale. Psychol Rep 10:799-812. CrossRef

Pontifex MB, Scudder MR, Brown ML, O’Leary KC, Wu CT, Themanson JR, Hillman $\mathrm{CH}$ (2010) On the number of trials necessary for stabilization of error-related brain activity across the life span. Psychophysiology 47: 767-773. CrossRef Medline

Raine A (2006) Schizotypal personality: neurodevelopmental and psychosocial trajectories. Annu Rev Clin Psychol 2:291-326. CrossRef Medline

Reinhart RM, Woodman GF (2014) Causal control of medial-frontal cortex governs electrophysiological and behavioral indices of performance monitoring and learning. J Neurosci 34:4214-4227. CrossRef Medline

Reinhart RMG, Woodman GF (2015a) Enhancing long-term memory with stimulation tunes visual attention in one trial. Proc Natl Acad Sci U S A 112:625-630. CrossRef Medline
Reinhart RMG, Woodman GF (2015b) The surprising temporal specificity following direct-current stimulation. Trends Neurosci. Advance online publication. Retrieved Jun. 17, 2015. doi: 10.1016/j.tins.2015.05.009. CrossRef Medline

Reinhart RMG, Zhu J, Park S, Woodman GF (2015) Synchronizing theta oscillations with direct-current stimulation strengthens adaptive control in the human brain. Proc Natl Acad Sci U S A 112:9448-9453. CrossRef Medline

Sadleir RJ, Vannorsdall TD, Schretlen DJ, Gordon B (2010) Transcranial direct current stimulation (tDCS) in a realistic head model. Neuroimage 51:1310-1318. CrossRef Medline

Sanders GS, Gallup GG, Heinsen H, Hof PR, Schmitz C (2002) Cognitive deficits, schizophrenia, and the anterior cingulate cortex. Trends Cogn Sci 6:190-192. CrossRef Medline

Schultz W, Dickinson A (2000) Neuronal coding of prediction errors. Annu Rev Neurosci 23:473-500. CrossRef Medline

Servan-Schreiber D, Printz H, Cohen JD (1990) A network model of catecholamine effects: gain, signal-to-noise ratio, and behavior. Science 249: 892-895. CrossRef Medline

Smith A, Li M, Becker S, Kapur S (2006) Dopamine, prediction error and associative learning: a model-based account. Network 17:61-84. CrossRef Medline

Sutton RS, Barto AG (1998) Reinforcement learning: an introduction. Cambridge, MA: Massachusetts Institute of Technology.

Tong ZY, Overton PG, ClarkD (1996) Stimulation of the prefrontal cortex in the rat induces patterns of activity in midbrain dopaminergic neurons which resemble natural burst events. Synapse 22:195-208. CrossRef Medline

Tseng P, Hsu TY, Chang CF, Tzeng OJ, Hung DL, Muggleton NG, Walsh V, Liang WK, Cheng SK, Juan CH (2012) Unleashing potential: transcranial direct current stimulation over the right posterior parietal cortex improves change detection in low-performing individuals. J Neurosci 32:10554-10561. CrossRef Medline

Ursu S, Kring AM, Gard MG, Minzenberg MJ, Yoon JH, Ragland JD, Solomon M, Carter CS (2011) Prefrontal cortical deficits and impaired cognition-emotion interactions in schizophrenia. Am J Psychiatry 168:276-285. CrossRef Medline

Wagner T, Fregni F, Fecteau S, Grodzinsky A, Zahn M, Pascual-Leone A (2007) Transcranial direct current stimulation: a computer-based human model study. Neuroimage 35:1113-1124. CrossRef Medline

Walton ME, Devlin JT, Rushworth MF (2004) Interactions between decision making and performance monitoring within prefrontal cortex. Nat Neurosci 7:1259-1265. CrossRef Medline

Waltz JA, Schweitzer JB, Gold JM, Kurup PK, Ross TJ, Salmeron BJ, Rose EJ, McClure SM, Stein EA (2009) Patients with schizophrenia have a reduced neural response to both unpredictable and predictable primary reinforcers. Neuropsychopharmacology 34:1567-1577. CrossRef Medline

Woodman GF, Luck SJ (2003) Serial deployment of attention during visual search. J Exp Psychol 29:121-138. CrossRef Medline

Woodward ND, Cowan RL, Park S, Ansari MS, Baldwin RM, Li R, Doop M, Kessler RM, Zald DH (2011) Correlation of individual differences in schizotypal personality traits with amphetamine-induced dopamine release in striatal and extrastriatal brain regions. Am J Psychiatry 168:418 426. CrossRef Medline

Yang CR, Seamans JK (1996) Dopamine D1 receptor actions in layers V-VI rat prefrontal cortex neurons in vitro: modulation of dendritic-somatic signal integration. J Neurosci 16:1922-1935. Medline

Yin HH, Knowlton BJ (2006) The role of the basal ganglia in habit formation. Nat Rev Neurosci 7:464-476. CrossRef Medline 